\title{
Key Elements of Sulfide Modification in the Sulfur-based Free-cutting Steel
}

\author{
Xu Li ${ }^{1, a}$, Zongze Huang ${ }^{2, b}$, Jinmin $\mathrm{An}^{2, \mathrm{c}}$, Yanxin $\mathrm{Wu}^{1, \mathrm{~d}}$, Jie $\mathrm{Xu}^{1, \mathrm{e}}$, Jianxun $\mathrm{Fu}^{\star 1, \mathrm{f}}$ \\ ${ }^{1}$ State Key Laboratory of Advanced Special Steel; Shanghai Key Laboratory of Advanced \\ Ferrometallurgy; School of Materials Science and Engineering, Shanghai University, Shanghai \\ 200072, China \\ ${ }^{2}$ State Key Laboratory of Development and Application Technology of Automotive Steels (Baosteel \\ Group), Shanghai Baoshan 20190, China \\ ali_xu@hotmail.com, bzhuang@baosteel.com, canjinmin@baosteel.com, \\ d wuyanxin@shu.edu.cn, exiabaxujie@163.com, ${ }^{\dagger}$ fujianxun@shu.edu.cn
}

Keywords: the sulfur-based free-cutting steel; machinability; MnS; complex inclusions

Abstract: Sulfides are beneficial inclusion in free-cutting steel, and can cause chips to break easily as an internal source of stress concentration when cutting steel, and also lubricate the tool and workpiece, thus reducing tool wear and improving machinability. Sulfide morphology directly determines the performance of the free-cutting steel, and it is possible to improve the machinability of the free-cutting steel by changing the $\mathrm{MnS}$ inclusions into small, dispersive, spherical or spindle-shaped inclusions, thus making them difficult to deform. In aluminum-killed steel treated with $\mathrm{Ca}$ or $\mathrm{Mg}$, there are numerous small and dispersive complex inclusions with an oxide core $(\mathrm{CaO} \cdot \mathrm{Al} 2 \mathrm{O} 3$ or $\mathrm{MgO} \cdot \mathrm{Al} 2 \mathrm{O} 3)$ and a sulfide surface layer $((\mathrm{Mn}, \mathrm{Ca}) \mathrm{S}$ or $(\mathrm{Mn}, \mathrm{Mg}) \mathrm{S})$. $\mathrm{Mg}$ can form simple oxides like $\mathrm{MgO}, \mathrm{MgS}$ or Mg-O-S. Mg can also form complex inclusions with an oxide core (MgO) and sulfide surface layer (MnS or Mn-Mg-S).

\section{Overview of Sulfide in Sulfur-based Free-cutting Steel}

The sulfide in sulfur-based free-cutting steel usually exists as (FeMn)S[1]. MnS are beneficial inclusions which can cause chips to be easily broken as an internal source of stress concentration when cutting steel, and can also lubricate the tool and workpiece and reduce tool wear, thus improving machinability[2,3]. $\mathrm{MnS}$ is one of the most common plastic nonmetallic inclusions in free-cutting steel, and is commonly used to improve machinability. The size, shape and distribution of $\mathrm{MnS}$ have a significant impact on the performance of the resulting steel. MnS can suppress the grain growth and promote the precipitation of intragranular ferrite, by improving $\mathrm{w}(\mathrm{Mn}) / \mathrm{w}(\mathrm{S})$ to generate more $\mathrm{MnS}$ while decreasing the generation of $\mathrm{FeS}$, which has a low melting point, thus finally improving the high temperature ductility of the steel[4].

$\mathrm{MnS}$ has good deformability and is easy to extend along the rolling direction in the rolling process, which causes anisotropy and significantly decreases the transverse properties of the material[5], and these elongated $\mathrm{MnS}$ inclusions are ready sources of cracks and expansion channels in slab steel, thus reduce the life of the material[6]. In order to suppress such harmful effects, it is helpful to form hard inclusions which are difficult to deform by adding an appropriate amount alloying elements, like $\mathrm{Ca}$, $\mathrm{Ti}, \mathrm{Mg}, \mathrm{RE}$ and so on. These hard inclusions distribute around the $\mathrm{MnS}$ and suppress its deformation, and make the MnS spindle-shaped or spherical $(\mathrm{L} / \mathrm{W} \leqslant 3)$. Such inclusions deform less during hot processing, and this steel has good machinability.

\section{Modification Mechanism and Route of Ca on Sulfides}

$\mathrm{Ca}$ is the currently most widely used alloying element to modify sulfides. The works of Averin[7], Lou[8], and Jiang et al.[9] have shown that Ca can partially transform MnS into CaS, and they can form a solid solution with each other to generate a new phase of (Mn,Ca)S. The hardness of (Mn, Ca)S is relatively high and the ductility is relatively low, and thus it can improve the transverse impact 
toughness of the steel after rolling. Carl[10] studied the effects of Ca treatment on inclusions in steel, and found that some of the $\mathrm{Ca}$ in steel combines with $\mathrm{Al} 2 \mathrm{O} 3$ and forms liquid calcium-aluminate, which can be the nucleation core of $(\mathrm{Mn}, \mathrm{Ca}) \mathrm{S}$ inclusions in the subsequent solidification process.

$\mathrm{Ca}$ is the strongest alloying element to form a sulfide with sulfur, and thus is often used as a modifier of $\mathrm{MnS}$. The modification mechanism of $\mathrm{Ca}$ on $\mathrm{MnS}$ is mainly providing high melting point hard nucleation cores and making $\mathrm{MnS}$ precipitate on these, or Ca combining with $\mathrm{MnS}$ to form a new solid solution. As is shown in Fig. 1[11], Ca and $\mathrm{MnS}$ combine to form ( $\mathrm{Mn}, \mathrm{Ca}) \mathrm{S}$, which is smaller in size and has weaker deformability. It also generally attaches to the surface of the oxide, thus avoiding the generation of large size pure $\mathrm{MnS}$. The modification mechanism can also be a combination of aforementioned two methods. Hu Junhui[12] found experimentally that there are large amounts of dispersed high melting point oxides in molten steel if $\mathrm{Ca}$ is added before vulcanization. Moreover, liquid $\mathrm{MnS}$ attaches to the oxide core and precipitates in the form of $(\mathrm{Mn}, \mathrm{Ca}) \mathrm{S}$ in the solidification front, and generally takes on the spherical surface structure due to the liquid's surface tension, thereby improving the morphology of sulfides. Chang Kaidi et al.[13] found that the inclusions are $(\mathrm{Mn}, \mathrm{Ca}) \mathrm{S}$ in the shape of spindles or ellipsoids when the Ca content in the molten steel is low, while they transform into the spherical $\mathrm{CaS}$ as the Ca content increases in the molten steel.

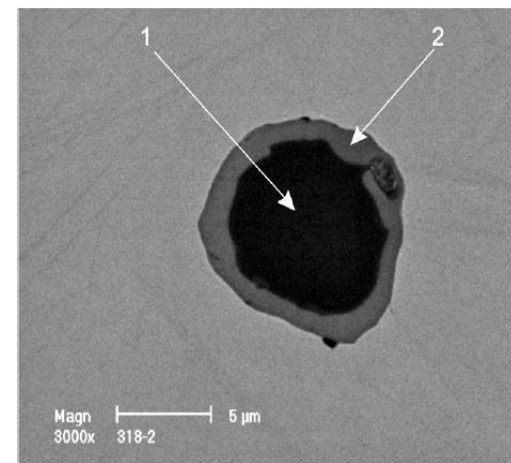

Fig. 1 Composite oxysulfide[11]

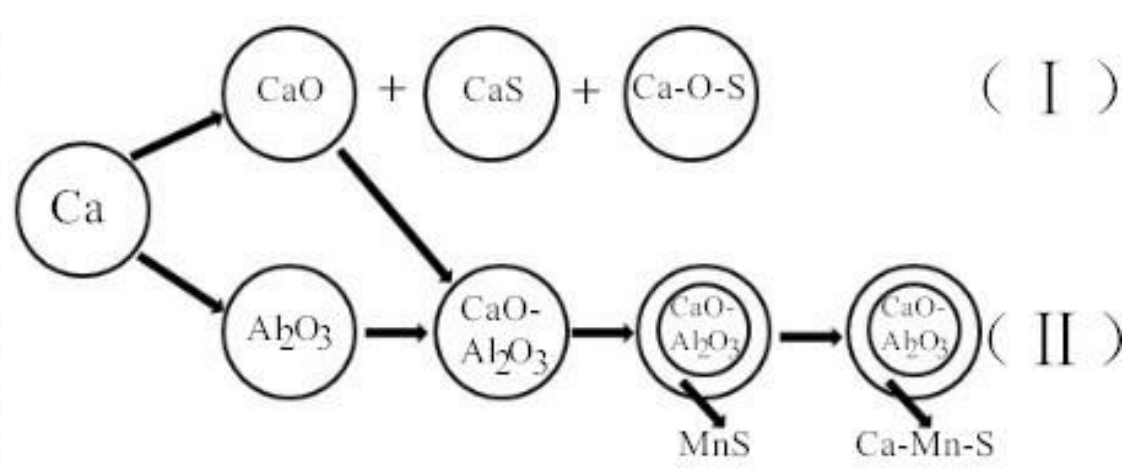

Fig. 2 Modification route of $\mathrm{Ca}$ on sulfides

$(1 \mathrm{CaO} \cdot \mathrm{Al} 2 \mathrm{O} 3,2(\mathrm{Mn}, \mathrm{Ca}) \mathrm{S})$

Fig. 2 shows the modification route of the inclusions produced with Ca treatment pf molten steel. $\mathrm{Ca}$ can generate $\mathrm{CaO}, \mathrm{CaS}$ or $\mathrm{Ca}-\mathrm{O}-\mathrm{S}$ with the oxygen and sulfur in molten steel as a deoxidizer and desulfurizer. If $\mathrm{Ca}$ is added to aluminium-killed steel, $\mathrm{Ca}$ combines with $\mathrm{Al} 2 \mathrm{O} 3$ in the molten steel and generates $\mathrm{CaO} \cdot \mathrm{Al} 2 \mathrm{O} 3$ as the nucleation core of $\mathrm{MnS}$, and finally forms complex inclusions with an oxide core $(\mathrm{CaO} \cdot \mathrm{Al} 2 \mathrm{O} 3)$ and a sulfide surface layer $(\mathrm{MnS}$ or $\mathrm{Ca}-\mathrm{Mn}-\mathrm{S})$.

\section{Modification Mechanism and Route of Mg on Sulfides}

$\mathrm{Mg}$ is a strong oxidant that can cause effective deoxidization and desulfurization. Inclusions in molten steel can be smaller and more dispersed after $\mathrm{Mg}$ treatment[14-16], and $\mathrm{MnS}$ tends to precipitate on magnesium oxide because $\mathrm{MnS}$ and $\mathrm{MgO}$ have the same $\mathrm{NaCl}$-type crystal structure and similar lattice constants (MnS: 0.522nm, MgO: 0.421nm).

Zhang[17] studied the influence on inclusions in molten steel of different sulfur contents after $\mathrm{Mg}$ treatment. As shown in Fig. 3, when the sulfur content in molten steel is low $(0.003 \%)$, the change in the composition of inclusions is as follows: $\mathrm{Al} 2 \mathrm{O} 3 \rightarrow \mathrm{MgAl} 2 \mathrm{O} 4 \rightarrow \mathrm{Mg}-\mathrm{Al}-\mathrm{O}-\mathrm{S} \rightarrow \mathrm{Mg}-\mathrm{O}-\mathrm{S}$; when the sulfur content in molten steel is high $(0.045 \%, 0.050 \%)$, the change in the composition of inclusions is: $\mathrm{Al} 2 \mathrm{O} 3 \rightarrow \mathrm{Mg}-\mathrm{S}(-\mathrm{O})+\mathrm{MnS}$. At the same time, elongated $\mathrm{MnS}$ in molten steel transforms into spindle-shaped $\mathrm{MgS} \cdot \mathrm{MgO}$ or $\mathrm{MgS} \cdot \mathrm{MnS} \cdot \mathrm{MgO}[18]$.

Fig. 4 shows the modification route of the inclusions by $\mathrm{Mg}$ treatment in molten steel. $\mathrm{Mg}$ can generate $\mathrm{MgO}, \mathrm{MgS}$ or $\mathrm{Mg}-\mathrm{O}-\mathrm{S}$ with the oxygen and sulfur in molten steel acting as a deoxidizer and desulfurizer. $\mathrm{Mg}$ can also form complex inclusions with an oxide core $(\mathrm{MgO})$ and a sulfide surface layer ( $\mathrm{MnS}$ or $\mathrm{Mn}-\mathrm{Mg}-\mathrm{S}$ ). If $\mathrm{Mg}$ is added to the aluminum-killed steel, $\mathrm{Mg}$ combines with $\mathrm{Al} 2 \mathrm{O} 3$ in 
molten steel and generates $\mathrm{MgO} \cdot \mathrm{Al} 2 \mathrm{O} 3$ as the nucleation core of $\mathrm{MnS}$, and finally forms complex inclusions with an oxide core (MgO·Al2O3) and sulfide surface layer ( $\mathrm{MnS}$ or $\mathrm{Mg}-\mathrm{Mn}-\mathrm{S})$.

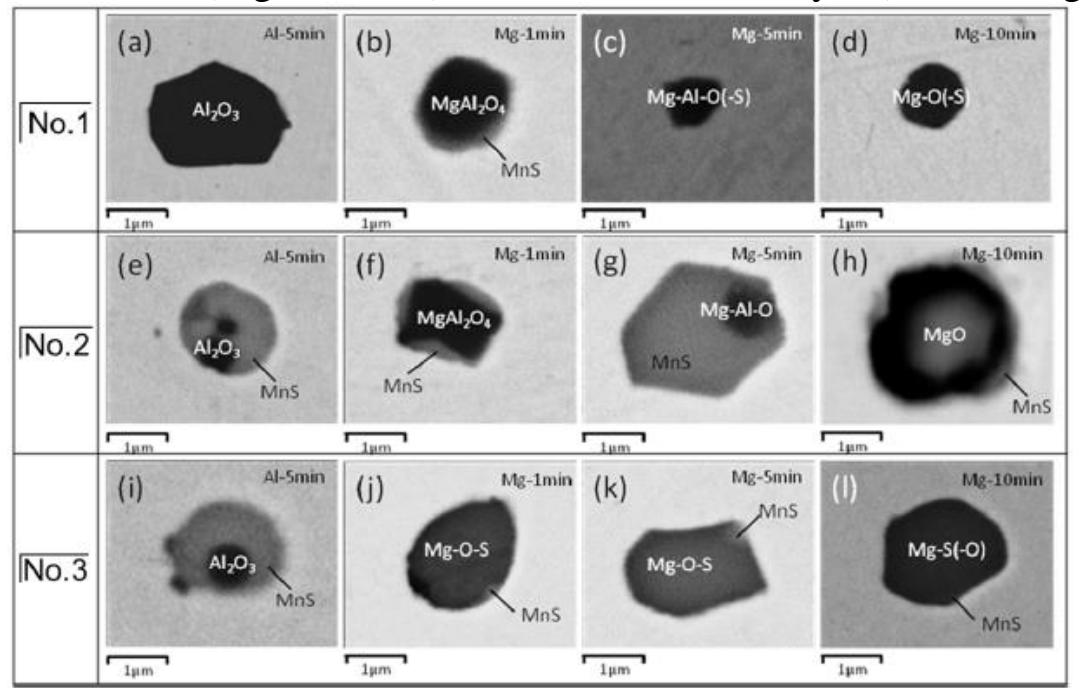

Fig. 3 Scanning electron micrographs and EDS analysis of inclusions with different sulfur contents[17]

(No.1 is low sulfur content, No.2 and No.3 are high sulfur content)

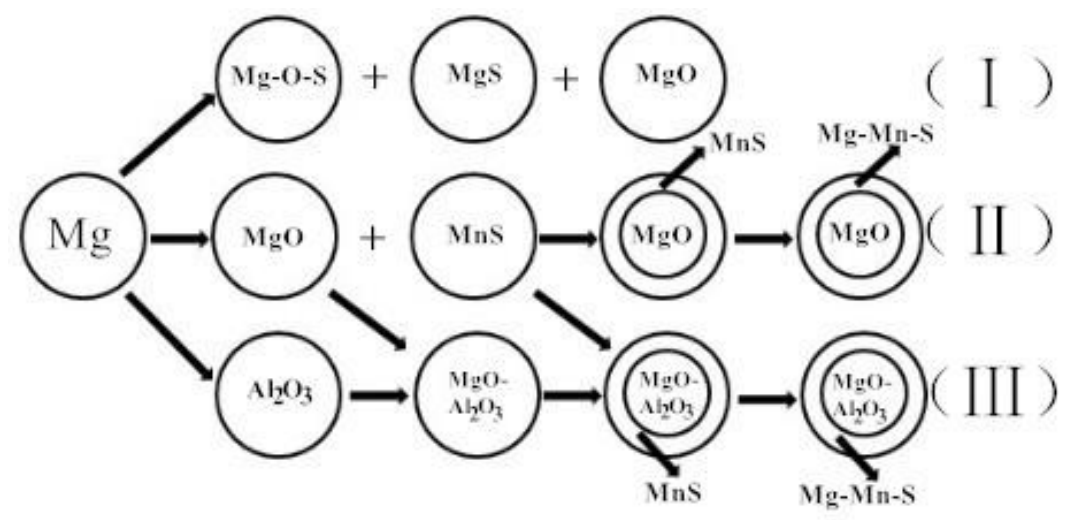

Fig. 4 Modification route of Mg on sulfides

\section{Outlook of Modification of Sulfides by Mg and Ca Treatment}

Aichi Steel Corporation and Toyota Central Research Institute have jointly developed a kind of lead-free vehicle free-cutting steel. Aichi Steel Corporation has developed a kind of sulfur-based free-cutting steel with better machinability than the lead-based free-cutting steel through an improved smelting process, and this "currently the world's best lead-free free-cutting steel with the best machinability", and is used to produce automotive crankshafts by Toyota Motor Corp[2,19]. Its technical route is modifying the sulfide by composite treatment of $\mathrm{Mg}$ and $\mathrm{Ca}$, and thus forming composite inclusions with a hard core and a sulfide surface layer. This kind of composite inclusion is extremely helpful in improving the properties of free-cutting steel, and thus it is valuable to further study the modification mechanism of the sulfide in molten steel by composite treatment of $\mathrm{Mg}$ and Ca.

\section{Acknowledgments}

This work is supported by the Foundation of State Key Laboratory of Development and Application Technology of Automotive Steels (Baosteel Group). 


\section{References}

[1] Lou D, Cui K, Wu X, Zhou F. Behaviour of MnS during hot deformation(In Chinese)[J]. Journal of Iron and Steel Research, 1996, 06: 11-14.

[2] Yuan W, Wang F. Present research status and prospects on free cutting steel at home and abroad(In Chinese)[J]. Research on Iron and Steel, 2008, 05: 56-62.

[3] Jiang G, Gu L, Shi Z, Chen Y. General situation and trend for free-cutting steel(In Chinese)[J]. Sichuan Metallurgy, 2006, 05: 10-14.

[4] Liu X, Wang X, Wang W, Zhang L, Zhou Y. Effect of the Mn/S mass ratio on the high temperature ductility of the low carbon steel under low strain rate(In Chinese)[J]. Chinese Journal of Engineering, 2000, 05: 427-430.

[5] Li Y, Zhu F, Cui F, Fang K. Analysis of forming mechanism of lamination defect of steel plate(In Chinese)[J]. Journal of Northeastern University(Natural Science), 2007, 07: 1002-1005.

[6] Domizzi G, Anteri G, Ovejero-Garcia J. Influence of sulphur content and inclusion distribution on the hydrogen induced blister cracking in pressure vessel and pipeline steels[J]. Corrosion Science, 2001, 43(2): 325-339.

[7] Averin V V, Gubenko S I, Okenko A P. The Composition and Deformability of Sulfide Inclusions in Steels Microalloyed With Rare Earth and Alkali Earth Metals[J]. Izv. Akad. Nauk SSSR, Met, 1982 (6): 82-84.

[8] Lou D, Cui K, Jia Y. Study on the machinability of resulfurized composite free-cutting steels[J]. Journal of materials engineering and performance, 1997, 6(2): 215-218.

[9] Laizhu J, Kun C, Hänninen H. Effects of the composition, shape factor and area fraction of sulfide inclusions on the machinability of re-sulfurized free-machining steel[J]. Journal of materials processing technology, 1996, 58(2): 160-165.

[10] Blais C, L'Espérance G, LeHuy H. Development of an integrated method for fully characterizing multiphase inclusions and its application to calcium-treated steels[J]. Materials characterization, 1997, 38(1): 25-37.

[11] Lis T. Modification of oxygen and sulphur inclusions in steel by calcium treatment[J]. Metalurgija, 2009, 48(2): 95-98.

[12] $\mathrm{Hu} \mathrm{J}$. Thermodynamic analysis of sulfide precipitation in low-carbon high-sulfur high-phosphorus steels in solidification process(In Chinese)[J]. Baosteel Technology, 2005, 05: 60-65+68.

[13] Chang K, Zhao H, Zhang H, Zhang W, Zhang Y, Wang G, Li F. Observation on sulphide inclusions morphology of sulphur- containing microalloyed steel after rolling(In Chinese)[J]. Heat Treatment of Metals, 2006, 09: 60-64.

[14] Yang J, Yamasaki T, Kuwabara M. Behavior of inclusions in deoxidation process of molten steel with in situ produced Mg vapor[J]. ISIJ international, 2007, 47(5): 699-708.

[15] $\mathrm{Fu} \mathrm{J,} \mathrm{Yu} \mathrm{Y,} \mathrm{Wang} \mathrm{A.} \mathrm{Inclusion} \mathrm{modification} \mathrm{with} \mathrm{Mg}$ treatment for 35CrNi3MoV steel[J]. Journal of Materials Science and Technology-Shenyang, 1998, 14: 53-56.

[16] Jiang Z, Zhuang Y, Yang L. Effect of Modification Treatment on Inclusions in 430 Stainless Steel by Mg-Al Alloys[J]. Journal of Iron and Steel Research, International, 2013, 20(5): 6-10.

[17] Zhang T, Wang D, Liu C. Modification of Inclusions in Liquid Iron by Mg Treatment[J]. Journal of Iron and Steel Research, International, 2014, 21: 99-103. 
[18] Zhang T, Wang D, Jiang M. Effect of Magnesium on Evolution of Oxide and Sulphide in Liquid Iron at $1873 \mathrm{~K}[\mathrm{~J}]$. Journal of Iron and Steel Research, International, 2014, 21(12): 1073-1080.

[19] Koumoto T, Nishi T, Mori M, et al. Development of Non-Lead-Added Free-Cutting Steel for Automobile Parts[R]. SAE Technical Paper, 2004. 